\title{
A Brief Study on the Qualities of an Effective Sentence
}

\author{
Xiu Yu \\ Qingdao University of Science \& Technology, Qingdao, China
}

\begin{abstract}
This paper aims to introduce the five essential qualities of an effective sentence in English, that is, correctness, clearness, unity, coherence and emphasis. By analyzing these essential qualities, English learners can make and use English sentences more effectively and efficiently.
\end{abstract}

Index Terms - correctness, clearness, unity, coherence, emphasis

\section{INTRODUCTION}

As we all know, sentence is a basic unit for people to communicate with others. In English, a complete sentence should be structurally complete, that is, it should contain at least a subject and a predicate. In form, it should begin with a capital letter and end with a full stop, or a question mark, or an exclamation mark. To be effective, a sentence should consist of the following qualities, that is, correctness, unity, clarity, coherence and emphasis (Wang, 2003).

\section{The Five Essential Qualities of An EfFective Sentence}

\section{A. Correctness}

The first quality of an effective sentence is correctness, that is, the sentence should be grammatically correct. For Chinese learners, they usually encounter two kinds of language difficulties in regard to this quality, that is, sentence fragments and danglers.

1. Sentence fragments

Grammatical correctness requires that a sentence possesses a subject and a predicate verb or with either of them stated or implied. A sentence lacking either of the essential elements is grammatically wrong and should not be regarded as a sentence but only a fragment (Wang, 2003). For example:

(1) Fragment: The problem being that a lot of college students can not find their ideal job after graduation.

Sentence: The problem is that a lot of college students can not find their ideal job after graduation.

(2) Fragment: He told us to go to the corner of the street. Leaving us to find the way to the new bar.

Sentence: He told us to go to the corner of the street, leaving us to find the way to the new bar.

2. Danglers

A dangler is a kind of grammatical error because it is an element unrelated to any word in a sentence. "Though it may appear in any part of the sentence, it usually occurs at the beginning. Since the subject in the sentence with a dangler is not the subject for the action described by the dangler, the way to correct this kind of error is either to supply a subject or to change the dangling phrase into a clause" (Wang, 2003, p. 47). For instance:

(1) Dangling: Opening the window, a lovely little girl caught his eye.

Revised: Opening the window, he saw a lovely little girl.

Or: When he opened the window, a lovely little girl caught his eye.

(2) Dangling: To win the English speaking competition, the first interview should be passed.

Revised: To win the English speaking competition, a student should pass the first interview.

Or: If a student wants to win the English speaking competition, he or she should pass the first interview.

(3) Dangling: Although as pretty a baby as his elder sister, his birth was practically unnoticed.

Revised: Although as pretty a baby as his elder sister, he was not noticed when he was born.

(4) Dangling: After watching the movie, what impressed him most is Alice's courage.

Revised: After watching the movie, he was impressed by Alice's courage.

Or: After he has watched the movie, what impressed him most is Alice's courage.

(5) Dangling: On entering the shop, a noisy sound was heard.

Revised: On entering the shop, he heard a noisy sound.

Or: When they entered the shop, a noisy sound was heard.

(6) Dangling: Looking out of the window, a well-dressed man attracted his attention.

Revised: Looking out of the window, he saw a well-dressed man.

Or: When he looked out of the window, a well-dressed man attracted his attention.

From the above-mentioned examples, it can be seen that fragments and danglers are undesirable grammatical mistakes. Thus, for English learners, they should have a clear understanding of the first essential quality of a sentence, 
that is, correctness. In that case, they can avoid writing and making incomplete sentences and such grammatical errors.

\section{B. Clearness}

To achieve the purpose of communication, a sentence's meaning should be clear. However, misunderstanding and ambiguity are often caused by misplaced modifiers, vague references of pronouns, vague comparisons and confusing shifts, etc.

1. Misplaced modifiers

The meaning of a sentence can be changed dramatically by changes in the position of modifiers. For example:

He was invited to a ball this evening.

He was invited this evening to a ball.

She pretended not to know the truth.

She did not pretend to know the truth.

In the first two sentences, the modifier is "this evening". It is used to modify "the ball" and "be invited" respectively. In the first sentence, people can know that the ball is held this evening. And the second sentence means the time he received his invitation is this evening. Similarly, the last two sentences' meanings are also totally different by the changes of the position of the modifier "not". The former sentence shows that she knew the truth. On the contrary, the latter one implies that she did not know the truth.

Generally speaking, a modifier should be placed next or as close as possible to the words it modifies (Wang, 2003). Misplaced modifiers may result in ambiguity or misunderstanding. For instance:

Ambiguous: The idea he mentioned at first sounded good.

In this example, the modifier "at first" is ambiguous because it can modify "the idea" or "the idea he mentioned sounded good". Thus, the sentence can be revised as "The idea he first mentioned sounded good" or "The idea he mentioned sounded good at first". Here are more examples:

(1) Ambiguous: They sold a computer to the store that was damaged.

Improved: They sold a computer that was damaged to the store.

(2) Ambiguous: I watched a touching story in a TV program about college students.

Improved: I watched a touching story about college students in a TV program.

2. Vague references of pronouns

Ambiguity in the meaning of a sentence is sometimes caused by a pronoun and it's vague reference. When people are speaking or writing, they should be sure that the reference of a pronoun is clear. "If the pronoun has an antecedent — as nearly all nouns have - the antecedent should be unmistakable. The reader should never be in doubt as to what word or idea the pronoun refers to; for if there is uncertainty the whole sentence may be confusing" (Wang, 2003, p. 54). For example:

She was knocked down by a car, but it was not serious.

He told my brother that he was right.

In each of the two faulty sentences there is a pronoun with ambiguous reference. In the first sentence, the only noun in the second sentence is "car", but "it" does not refer to it. So the sentence can be revised as "She was knocked down by a car, but was not badly hurt". In the second sentence, the second "he" can cause misunderstanding because it can refer to the subject or the "my brother". Therefore, the sentence can be rewritten as the following: "I'm right," he said to my brother, or "You are right," he said to my brother, or "He thought that he was right and said so to my brother".

More examples:

(1) Ambiguous: The railway station was crowded with people. Some were talking and laughing loudly. Others were drinking and smoking. That made the young woman sick.

Improved: The railway station was crowded with people. Some were talking and laughing loudly. Others were drinking and smoking. That atmosphere made the young woman sick.

(2) Ambiguous: Jack held a hamburger in one hand and the mobile phone in the other. He kept eating it while he talked.

Improved: Jack held in one hand the mobile phone and in the other a hamburger, which he kept eating while he talked.

(3) Ambiguous: The poet spent a lot of her time writing, but none of them was published during his lifetime.

Improved: The poet spent a lot of her time writing, but none of her poems was published during his lifetime.

(4) Ambiguous: The student used some figures of speech in his paper, which the teacher disapproved of.

Improved: The teacher disapproved of the student's use of figures of speech in his paper.

3. Vague comparisons

Ambiguous and cofusing comparisons should be avoided in English sentences. In other words, the thing to be compared must be specified. "When comparing to other members of its own class, one must exclude it from the group by adding 'other', 'else', or any other word similar in meaning. But when comparing a thing to members of another group, one does not need to do so. Special care should be taken when the superlative degree of wither an adjective or an adverb is used" (Wang, 2003, p. 60). For example:

(1) Vague: His voice is more attractive than I.

Improved: His voice is more attractive than mine. 
(2) Vague: Linda is more clever than any students in her class.

Improved: Linda is more clever than any other students in her class.

(3) Vague: The report he has made is more practical than Mary made.

Improved: The report he has made is more practical than the one Mary made.

Or: The report he has made is more practical than that Mary made.

4. Confusing shifts

Confusing shifts in structure can often cause ambiguity. For instance:

Shift: She did the homework assigned by the teacher and the lesson taught last class was reviewed.

In this sentence, the subject shifts from "she" to "the lesson" and the active voice shifts from the active to the passive.

That is to say, this sentence has confusing shifts in subject and voice. Therefore, the sentence can be revised by changing "the lesson" to "she" and the passive to active so as to have consisitency in both subject and voice.

Revised: She did the homework assigned by the teacher and reviewed the lesson taught last class.

More examples include cofusing shift in person or number, cofusing shift in tense and cofusing shift in mood.

(1) Shift: An important thing for the secretary to know is that when writing a report, you should not plagiarize (cofusing shift in person).

Revised: An important thing for the secretary to know is that when writing a report, she should not plagiarize.

(2) Shift: Those who want to study history should sign his name on this sheet of paper (cofusing shift in number).

Revised: Those who want to study history should sign their names on this sheet of paper.

(3) Shift: He plays football every morning and drank coffee every afternoon (cofusing shift in tense).

Revised: He plays football every morning and drinks coffee every afternoon.

(4) Shift: Write a term paper and you should hand it in before next Monday (cofusing shift in mood).

Revised: Write a term paper and hand it in before next Monday.

\section{Unity}

In terms of meaning, a unified sentence should express a single complete thought. "It does not contain ideas that are not closely related, nor does it express a thought that is not complete by itself” (Ding, 1994, p. 54). For example:

Poor: Graduated from Qingdao University of Science and Technology last year, Wang Zonglin is very passionate and helpful to others.

In this sentence, the two parts of the sentence are not logically connected. It violates the principle of unity because people who graduated from Qingdao University of Science and Technology last year are not bound to be passionate and helpful to others. Therefore, this sentence can be rewritten as the following:

Revised: Wang Zonglin graduated from Qingdao University of Science and Technology last year. After graduation, he found a job and he was very popular among his colleges because he is very passionate and helpful to others.

Another example:

Poor: Ernest Hemingway is one of the famous novelists.

Revised: Ernest Hemingway is one of the famous novelists in the United States.

This first sentence is not effective because the idea expressed is incomplete: there is no mention of the time or country. Therefore, the second sentence is better because "in the United States" makes the sentence's meaning clear and complete.

In daily English learning, unnecessary repetition in a sentence is another kind of common violation of the principle of unity. Such as:

Wordy: I speak English equally as well as his sister.

This sentence is wordy because it repeats unnecessary words, that is "equally" and "as well as". The adverb "equally" means "to the same extent or degree", as in the sentence "These ways are equally important". In other words, the meaning of "equally" is similar to that of "as well as". Hence, it can be revised as the following: "I speak English equally as his sister" or "I speak English as well as his sister". Similar cases are offered in the following:

(1) Wordy: Did she intend to do it deliberately?

Revised: Did she intend to do it?

Or: Did she do it deliberately?

(2) Wordy: In this city, robbery has become a commonplace thing, a thing that occurs every day.

Revised: In this city, robbery has become a commonplace thing.

Or: In this city, robbery is a thing that occurs every day.

(3) Wordy: What they are trying to say is that in their opinion, Mr. Li should further his study in Canada.

Revised: What they are trying to say is that Mr. Li should further his study in Canada.

Or: In their opinion, Mr. Li should further his study in Canada.

(4) Wordy: This thief keeps appearing in this supermarket repeatedly.

Revised: This thief keeps appearing in this supermarket.

Or: This thief appears in this supermarket repeatedly.

(5) Wordy: That country has a population of three million people.

Revised: That country has three million people.

(6) Wordy: You can go to the supermarket when I returns back. 
Revised: You can go to the supermarket when I returns.

(7) Wordy: Miss Wang put a letter that came from abroad on Mr. White's table.

Revised: Miss Wang put a letter that from abroad on Mr. White's table.

\section{Coherence}

Coherence means that the parts of a sentence are so arranged that they stick together, and the thought progresses in a logical sequence. One way to achieve coherence is to resort to parallelism, which can clarify the relationship between a writer's parallel ideas, or between parallel parts of a single idea, by expressing similar ideas in similar grammatical forms. Generally speaking, many sentence elements can be placed in parallel structures (Wang, 2003). And a sentence by employing parallel structure can be more vivid and effective. For example:

Democrats can not say no to social programs; Republicans can not say no to military spending. The result is a tripled national debt and high interest rates. - M. Zuckerman

From the above-mentioned example, it can be seen that parallel construction is one of the most effective ways to make sentences emphatic and impressive. However, some English learners can not make coherent sentences because of the faulty parallel structure. For example:

Faulty: Frank is easy-going, considerate, and a generous man.

In this sentence, "easy-going" and "considerate" are adjectives, "a generous man" is a noun phrase. Obviously, they are not arranged in a logical order. Therefore, we can make use of parallel construction to make the sentence coherent, such as "Frank is an easy-going, considerate, and generous man" or "Frank is easy-going, considerate and generous". More examples are in the following:

(1) Faulty: Anna is not only clever but also worked hard.

Revised: Anna is not only clever but also hard-working.

(2) Faulty: My watch is either slow or yours is fast.

Revised: Either my watch is slow or yours is fast.

(3) Faulty: A man is judged not only by what he says but also by his deeds.

Revised: A man is judged not only by what he says but also by what he does.

Or: A man is judged not only by his words but also by his deeds.

(4) Faulty: Yesterday he lost his lovely pet so he could not eat well, drink well and have a good sleep.

Revised: Yesterday he lost his lovely pet so he could not eat well, drink well and sleep well.

(5) Faulty: Mary and I don't like sweet food, so she neither eats the candy nor I do.

Revised: Mary and I don't like sweet food, so neither she eats the candy nor I do.

(6) Faulty: She took the chocolate to the classroom but which she was given no opportunity to eat.

Revised: She took the chocolate to the classroom but was given no opportunity to eat.

(7) Faulty: They went to America with a boy from Mexico and who has a long hair.

Revised: They went to America with a boy who is from Mexico and who has a long hair.

(8) Faulty: He forgot that his project was due this Monday and his boss had said he would not accept late reports.

Revised: He forgot that his project was due this Monday and that his boss had said he would not accept late reports.

\section{E. Emphasis}

To emphasize means to show the relative importance of ideas in a sentence. Therefore, emphasis is an effective means to achieve impressive expression of people's ideas. There also a lot of ways to achieve emphasis including inversion, the passive voice, repetition, negative-positive statements, climatic order, rhetorical question and some kinds of sentences.

1. Inversion

When people want to emphasize an idea, they can move the point, out of order, to the front. Such as:

(1) Happy are those who receive this exciting news after a long time.

(2) Not for one second does he think he has any hope of going to abroad.

(3) Only last night did she find that his wallet was missing.

(4) So much does Jack worry about his work that he can not eat and sleep well.

(5) Quickly and impressively he said goodbye to his wife and children.

(6) Hardly had she finished her housework when the doorbell rang.

2. The passive voice

Although the active voice is precise and direct, the passive voice is more appropriate than the active as an emphatic device just as in the following sentences.

(1) The passagers have been injured in a train accident and they have been taken to hospital.

(2) The answer to the question was given by nobody other than the president.

(3) She is promoted to the manager of the Public Relations Department by Mr. Wang, who is her former director.

(4) In this war, thousands of people were driven from their hometown.

3. Repetition

Deliberate repetion in a sentence is a kind of means to achieve emphasis. For instance:

We are human and human beings are far from perfect. To be human implies that we will make mistakes. But it's more 
than that we feel human. We now feel titled.

4. Negative-positive statements

In this kind of sentences, people first state what is not the fact, and then what is. And this contrastive method cam make the idea emphatic. Such as:

There were so many faults in the presentation that the result was not a failure, but success.

5. Climatic order

Climatic order is the order that goes from the general to the specific or that goes from the least important to the most important (Wang, 2003). For example:

(1) I love my village, my city and my country.

(2) He lost his pet, his wallet and his honor.

6. Rhetorical question

A rhetorical question is a particular kind of question that it does not need an answer. When people encounter a rhetorical question, they will often reflect it for a moment. Generally, a rhetorical question is used for emphasis because it is often reserved for special purpose. Such as:

(1) Was you not at the scene of the ceremony?

(2) Didn't Sally tell you that you can not go to that room?

(3) If winter comes, can spring be far behind?

7. Different kinds of sentences to achieve emphasis

a. Simple and short sentences

A simple sentence has only one subject and one predicate. Simple short sentences are often used to make important or emphatic statements. Such as:

(1) He is not smart.

(2) She is beautiful.

b. Imperative or exclamatory sentences

Imperative or exclamatory sentences are emphatic. An imperative sentence usually expresses a request or command. e.g. Stop talking. An exclamatory sentence generally expresses a strong feeling or emotion. For instance:

(1) What a lovely boy!

(2) How careless she is!

c. Periodic sentences

In periodic sentences, the main and emphatic idea is commonly expressed at or near the end. For example:

Although the boy was interested in English, he decided to study maths at last.

d. Balanced sentences

Balanced sentence is a kind of sentence in which parallel ideas are expressed in parallel constructions. Because of the parallel structures, balanced sentences are usually impressive, forceful and emphatic. For instance:

In Plato's opinion man was made for philosophy; in Bacon's opinion philosophy was made for man. - Thomas Babington Macaulay

\section{CONCLUSION}

This paper mainly makes a study on the five essential qualities of an effective sentence in English, that is, correctness, clearness, unity, coherence and emphasis.

Correctness is the first quality of an effective sentence. It means that the sentence should be grammatically correct. As for English learners, they usually make two kinds of language mistakes which violates the principle of correctness, that is, sentence fragments and danglers. Sentence fragment is only a part of a sentence instead of a complete sentence. And a dangler is an element unrelated to any word in a sentence. In writing sentences, people should avoid making the above-mentioned grammatical errors.

Clearness is the second quality of an effective sentence. To achieve the purpose of communication, the meaning of a sentence should be clear. Nevertheless, ambiguity or misunderstanding usually occurs because of misplaced modifiers, vague references of pronouns, vague comparisons and confusing shifts and so on.

Unity is the third quality of an effective sentence. It requires that a sentence should express only one idea. And at the same time, the idea should be complete.

The fourth quality of an effective sentence is coherence. It means that different parts of a sentence should be arranged in a logical order. To achieve coherence, people usually resort to parallelism.

The last quality of an effective sentence that the author discussed is emphasis. To emphasize means to show the relative importance of ideas in a sentence. There are several ways to achieve emphasis, such as inversion, the passive voice, repetition, negative-positive statements, climatic order, rhetorical question, simple and short sentences, imperative and exclamatory sentences, periodic sentences and balanced sentences, etc.

By analyzing and examing a lot of examples, the author studied the five essential qualities of an effective sentence in detail, hoping to help English learners to make and use sentences effectively and appropriately. 


\section{REFERENCES}

[1] Bander, Robert G (1980). From Sentence to Paragraph. New York: Harper and Row, Publishers, Inc.

[2] Ding Wangdao (1994). A Handbook of Writing, Beijing: Foreign Language Teaching and Reaserch Press.

[3] Ge Chuangui (1992). The Writing of English. Shanghai: Shanghai Translation Press.

[4] Kress, Gunther (1982). Learning to Write. London: routledge\&Kegan Paul Ltd.

[5] Wang Yulong (2003). College Guide to Writing, Qingdao: Ocean University of China.

[6] Zhang Zhenbang (2000). A New English Grammar Coursebook, Shanghai: Shanghai Foreign Language Education Press.

Xiu Yu was born in Qingdao, China in 1980. She received her M.A. degree in linguistics from Ocean University of China, China in 2007.

She is currently a teacher in the School of Foreign Languages, Qingdao University of Science \& Technology, Qingdao, China. Her research interests include psycholinguistics and cognitive linguistics.

$\mathrm{Mrs} \mathrm{Yu}$ is a member of the linguistic research center in the School of Foreign Languages, Qingdao University of Science \& Technology. 